\title{
Dreaming experience as a useful diagnostic clue for syncopal episodes
}

\author{
V. Chiesa ${ }^{a}$, P. Terranova ${ }^{b}$, A. Vignoli ${ }^{a}$ and M. P. Canevini ${ }^{a}$ \\ ${ }^{a}$ Neurology Unit 2, Epilepsy Center, San Paolo Hospital, Department of Medicine, Surgery and Dentistry, University of Milan, Milan; and \\ ${ }^{\mathrm{b}}$ Cardiology Unit, San Paolo Hospital, Milan, Italy
}

\section{Keywords:}

convulsion, dreaming

experience, generalized

seizure, seizure, syncope

Received 12 November 2010

Accepted 17 March 2011
Background: The differential diagnosis between epileptic seizures and syncopes is a common occurrence in clinical practice. The manifestations of seizure and syncope sometimes overlap, and available diagnostic testing often not provides a conclusive answer. Syncope is often preceded by a symptom complex characterized by lightheadedness, generalized muscle weakness, giddiness, visual blurring, tinnitus, and gastrointestinal symptoms. These subjective symptoms are very important in guiding the diagnosis. In our experience, the impression of coming out of a dream after the syncopal episode is a subjective symptom commonly reported by patients, if questioned.

Methods: To verify the occurrence of dreaming experience after syncope and after generalized tonic-clonic seizures (GTCS) and its diagnostic value in differential diagnosis, we asked 100 patients with GTCS and diagnosis of idiopathic generalized epilepsy (Group 1) and 100 patients with a certain diagnosis of syncope (Group 2) whether they have never felt the impression of coming out of a dream after the loss of consciousness (GTCS or syncope, respectively).

Results: In Group 1, nobody referred the dreaming experience, whereas in the syncope group, $19 \%$ of patients referred this subjective symptom.

Conclusions: Dreaming experience seems to be an additional useful diagnostic clue for syncopal episodes, helping the clinician to differentiate them from seizures.

\section{Introduction}

The differential diagnosis between epileptic seizure and syncope is a common occurrence in clinical practice. Because convulsions occur in $12 \%$ of patients with syncope [1], the clinical manifestations of a seizure and syncope sometimes overlap and available diagnostic testing often fails to provide a conclusive answer [2]. Both EKG and 24-h EKG monitoring (Holter) have low sensitivity (5-10\%) in detecting a cardiac cause; on the other hand, EEG has a higher sensitivity $(50 \%)$ if performed in the first hours after seizure [1] but a low specificity. Accurate history taking is the first step and the most sensitive tool [2]. Syncope is often preceded by a symptom complex characterized by lightheadedness, generalized muscle weakness, giddiness, sweating, visual

Correspondence: Dr V. Chiesa, Centro Regionale per l'Epilessia Neurologia II, Azienda Ospedaliera San Paolo, Via Di Rudinì, 8, 20142 Milano, Italy (tel.: + 39028184 4201; fax: + 39025032 3159; e-mail: valentina.chiesa@ao-sanpaolo.it). blurring, tinnitus, and gastrointestinal discomfort. These subjective symptoms are very important in guiding the diagnosis. After the faint, the patients can also report some subjective feelings (e.g. residual weakness, nausea).

As in our clinical experience the sensation of coming out from a dream after the syncopal episode is a subjective symptom commonly reported by patients, if questioned, the aim of this study was to verify the occurrence of dreaming experience after syncope and after generalized tonic-clonic seizures (GTCS) and its diagnostic value in differential diagnosis.

\section{Patients and methods}

We prospectively investigated 100 patients with GTCS and certain diagnosis of idiopathic generalized epilepsy (Group 1) according to ILAE classification [3] followed at our Epilepsy Center (San Paolo Hospital of Milan, Italy) and 100 patients with a certain diagnosis of syncope (Group 2) according to Guidelines on 
Management of Syncope of European Society of Cardiology [4] referred to the Cardiological Unit of the same Hospital. The study was approved by the Ethics Committee of San Paolo Hospital, and participating subjects gave their informed consent.

The patients were collected over a period of 3 years (2006-2009). Besides physical examination and routine diagnostic tools (EEG and brain MRI for Group 1; EKG, 24-h EKG monitoring, Tilt-table testing for Group 2), a detailed clinical history was taken. Particularly, patients were asked about the subjective symptoms preceding and following the loss of consciousness and were also questioned whether they have never experienced the feeling of coming out of a dream after the loss of consciousness (GTCS or syncope, respectively). For this purpose, a questionnaire composed by the following three simple questions was used: (i) if the patient, after the loss of consciousness, has never experienced the feeling of coming out of a dream; if so (ii) if patient could remember the dream, and in this case, (iii) if the dream's content was pleasant or unpleasant.

Statistical analyses were conducted using the Statistical Package for Social Science (SPSS Inc., Chicago, IL, USA). Quantitative data are reported as mean \pm standard deviation (SD), and qualitative data are reported as frequency counts and percentages. Comparison of quantitative variables was made with unpaired Student's $t$-test, whilst categorical variables association was tested by the Pearson $\chi^{2}$ test.

\section{Results}

No differences in demographic characteristics of patients were detected between the two groups (Table 1). In Group 1, nobody referred the dreaming experience, whereas in the syncope group $19 \%$ of patients (4 men and 15 women) referred this subjective symptom. Amongst patients with syncope with convulsion, four patients ( 1 man and 3 women) referred the feeling of coming out of a dream $(20 \%)$. Only few patients $(n=4,21 \%)$ remembered the dream content, which in one case was a nightmare, whereas in the other three cases it was a pleasant one. In Group 2, 20 patients had

Table 1 Demographic characteristics of patients included in the study

\begin{tabular}{llll}
\hline & $\begin{array}{l}\text { Group 1 } \\
(n=100)\end{array}$ & $\begin{array}{l}\text { Group 2 } \\
(n=100)\end{array}$ & $P$-value \\
\hline Sex & $\begin{array}{c}38 \mathrm{M}, 62 \mathrm{~F} \\
(38 \% \mathrm{M}, 62 \% \mathrm{~F})\end{array}$ & $\begin{array}{c}36 \mathrm{M}, 64 \mathrm{~F} \\
(36 \% \mathrm{M}, 64 \% \mathrm{~F})\end{array}$ & 0.77 \\
Age (years) & $38.6 \pm 13.9$ & $40.6 \pm 21.0$ & 0.44 \\
\hline
\end{tabular}

Group 1, patients with generalized epileptic seizures; Group 2, patients with syncope.
Table 2 Demographic characteristics of patients who presented syncope with and without convulsions within Group 2

\begin{tabular}{llll}
\hline & $\begin{array}{l}\text { Patients with syncope } \\
\text { with convulsion } \\
(n=20)\end{array}$ & $\begin{array}{l}\text { Patients with syncope } \\
\text { without convulsion } \\
(n=80)\end{array}$ & $P$-value \\
\hline Sex & $9 \mathrm{M}, 11 \mathrm{~F}$ & $27 \mathrm{M}, 53 \mathrm{~F}$ & 0.35 \\
& $(45 \% \mathrm{M}, 55 \% \mathrm{~F})$ & $(34 \% \mathrm{M}, 66 \% \mathrm{~F})$ & \\
Age (years) & $36.7 \pm 20.5$ & $41.5 \pm 21.1$ & 0.36 \\
\hline
\end{tabular}

Table 3 Demographic characteristics of patients with and without dreaming experience following syncope within Group 2

\begin{tabular}{llll}
\hline & $\begin{array}{l}\text { Patients with } \\
\text { dreaming experience } \\
(n=19)\end{array}$ & $\begin{array}{l}\text { Patients without } \\
\text { dreaming experience } \\
(n=81)\end{array}$ & $P$-value \\
\hline Sex & $\begin{array}{c}4 \mathrm{M}, 15 \mathrm{~F} \\
(21 \% \mathrm{M}, 79 \% \mathrm{~F})\end{array}$ & $\begin{array}{c}32 \mathrm{M}, 49 \mathrm{~F} \\
(39 \% \mathrm{M}, 59 \% \mathrm{~F})\end{array}$ & 0.13 \\
Age (years) & $34 \pm 16.6$ & $42.1 \pm 21.7$ & 0.13 \\
\hline
\end{tabular}

syncope with convulsions (20\%): no differences in demographic characteristics were detected within Group 2, between patients who presented syncope with or without convulsion, nor between patients who referred or not the feeling of coming out of a dream after the loss of consciousness (Tables 2 and 3).

\section{Discussion}

Transient loss of consciousness is a common cause for emergency room visits and for hospitalization. Involuntary movements, often referred to as myoclonic jerks, may accompany syncope because of cardiovascular causes and create a differential diagnostic problem against seizure with important therapeutic and prognostic consequences [5,6]: despite the occurrence of many symptoms considered typical for syncope, sometimes distinguishing between seizure and syncope remains difficult, and convulsions secondary to syncope often result in an incorrect diagnosis of a seizure disorder $[2,5]$. About $40 \%$ of patients initially thought to have epileptic seizures were later found to have syncope with convulsions because of cardiovascular cause [7]. The misdiagnosis of patient with syncope with convulsions, and the consequent delays of adequate treatment starting, could expose the individual to the risk of injury or death [8]. Available diagnostic tools are often not adequate to clarify the etiology of loss of consciousness; an accurate clinical history, focusing on subjective symptoms preceding and following the episodes, and witness account are the most helpful diagnostic instruments [2]. In this context, every additional clue potentially helpful for clarifying the diagnosis could be precious: in our sample, the dreaming experience is a 
sensation commonly referred, if questioned, by patients with syncope with or without convulsions, whereas never referred after GTCS. Therefore, dreaming experience seems to be an additional useful diagnostic clue for syncopal episodes, helping the clinician to differentiate them from seizures.

\section{References}

1. McKeon A, Vaughan C, Delanty N. Seizure versus syncope. Lancet Neurol 2006; 5: 171-180.

2. Benton TJ, Narayanan D. Differentiating seizure and convulsive syncope: the importance of history taking. Postgrad Med 2008; 120: 50-53.

3. Engel J. A proposed diagnostic scheme for people with epileptic seizures and with epilepsy: report of the ILAE task force on classification and terminology. Epilepsia 2001; 42: 796-803.

4. The Task Force on Syncope, European Society of Cardiology. Guidelines on Management (Diagnosis and Treatment) of Syncope - Update 2004 - Executive Summary. Eur Heart J 2004; 25: 2054-2072.

5. Lempert T, Bauer M, Schmidt D. Syncope: a videometric analysis of 56 episodes of transient cerebral hypoxia. Ann Neurol 1994; 36: 233-237.

6. Bergfeldt L. Differential diagnosis of cardiogenic syncope and seizure disorders. Heart 2003; 89: 353-358.

7. Zaidi A, Clough P, Cooper P, Scheeper B, Fitzpatrick AP. Misdiagnosis of epilepsy: many seizure-like attacks have a cardiovascular cause. J Am Coll Cardiol 2000; 36: 181-184.

8. Kanjwal K, Karabin B, Kanjwal Y, Grubb BP. Differentiation of convulsive syncope from epilepsy with an implantable loop recorder. Int J Med Sci 2009; 6: 296-300. 